\title{
EL TRASFONDO CRISTIANO EN LA UTOPÍA DE TOMÁS MORO ${ }^{1}$
}

\author{
THE CHRISTIAN BACKGROUND IN THOMAS MORE'S «UTOPIA»
}

\author{
Jesús Caos Huerta Rodríguez \\ Universidad Pedagógica Nacional \\ (Subsede Ensenada) \\ jhuertar@edubc.mx
}

Fecha de Recepción: 22-08-2017

Fecha de Aceptación: 09-03-2018

\section{RESUMEN}

El presente trabajo se enfoca en la influencia de la tradición bíblica textual sobre el pensamiento de Tomás Moro. De manera específica son dos las áreas que se exploran: la idea de la comunidad de bienes y la imaginación profética. Ambas nociones, aunque de alguna manera se encuentran presentes en la tradición clásica griega, adquieren su concreción en determinados textos bíblicos. A partir de ello se concluye que el trasfondo cristiano, a través de sus textos fundantes, tiene una relevancia primordial en las ideas sobre las cuales se construye el pensamiento utópico de Moro. Así, aunque es indudable que el elemento griego subyace bajo las principales ideas de Utopía, los textos bíblicos son un cauce primordial que alimenta su obra.

Palabras Clave: Utopía; comunidad de bienes; imaginación profética; apocalíptica, textos bíblicos.

${ }^{1}$ Este trabajo se ha realizado en el marco del proyecto de investigación I+D del Ministerio de Economía y Competitividad (España) titulado Edición y estudio de textos bíblicos y parabíblicos (FFI2017-86726-P). 


\section{AbSTRaCT}

This paper focuses on presenting the influence of a textual-biblical tradition on Thomas More's thinking. Especially, this paper explores two different areas: the idea of commonwealth, and prophetic imagination. Both concepts, though present in classical Greek tradition, gain meaning in specific biblical texts. For that reason, it is concluded that the Christian background, through its founding texts, has primordial relevance to ideas which More's utopic thinking is built. Therefore, although there is no doubt that this Greek element lies behind Utopia's main ideas, it is clear that biblical texts are a main source for More's work.

KEY WORDS: Utopia, commonwealth; prophetic imagination; apocalyptica, biblical texts.

\section{INTRODUCCIÓN}

La Utopía es una obra que hereda un repertorio de ideas procedentes de la Antigüedad Clásica, en particular de la griega, y las combina de una manera creativa con el escenario cultural de la Europa renacentista. Además, la Utopía de Moro también tiene un notable trasfondo cristiano que ha sido documentado cuidadosamente desde una perspectiva bíblica. ${ }^{2} \mathrm{Al}$ mismo tiempo, la obra de este humanista, como cualquier otra literatura utópica, posee un fuerte sentido de protesta e inconformidad social que le lleva a repensar de una manera crítica el horizonte político, económico y social de su momento. A partir de estos tres componentes enumerados, la cultura clásica, la tradición cristiana y la inconformidad social, la obra de Moro sigue ofreciendo determinados matices de análisis. El presente escrito pretende explorar los dos últimos aspectos señalados. Así pues se parte de la premisa que, sin estos dos elementos juntos, esto es, la tradición cristiana con su empuje contracultural y el tono de protesta ante la injusticia social implícito en cualquier proyecto utópico, la obra de Moro no pasa de ser un recurso imaginario de una sociedad ideal que no tiene ningún otro fin que ser simplemente una narración fantástica.

Tradicionalmente se suele identificar los elementos de la cultura griega como los antecedentes más inmediatos implícitos en la Utopía de Moro; sin embargo, también existen otras influencias culturales en el humanista renacentista. No se puede negar el aporte que han tenido las ideas procedentes del mundo griego sobre el pensamiento de Moro. Así pues, uno de los mayores afluentes que nutre al humanista inglés es la República de Platón (CORRIGAN, 1990). Resulta sencillo identificar, entre estos dos autores, numerosos paralelismos que hablan de la dependencia de las ideas platónicas en las descripciones de Utopía. Ambos pensadores tienen en común la idea de una sociedad basada en la división de las funciones y del trabajo social como requisito para la organización armónica de la República. De igual manera, los dos consideran el bien común como el elemento primordial frente a los intereses del individuo. Así lo general trasciende a los fines particulares y el

\footnotetext{
2 Al respecto Marc'hadour ha dado cuenta de las referencias bíblicas presentes en la obra de Tomás Moro a través de una extensa publicación en 5 volúmenes.
} 
mejor ciudadano es aquel que estima su propio bien como subordinado o coincidente con el de los demás. Para poder lograr esta coincidencia entre el bien individual y el colectivo, el programa educativo ocupa un lugar destacado en los proyectos de las dos repúblicas, pues únicamente a través de una formación intencional y sistemática impartida desde la niñez es posible alcanzar el ideal que persiguen tanto Platón como Moro.

Sin embargo, el paralelismo entre estos dos autores no se reduce únicamente a las ideas contenidas en la República de Platón. También hay otros «espacios literarios» donde la dependencia de Moro con respecto a la obra platónica es palpable. En los diálogos platónicos de Timeo y Critias, Platón habla sobre la existencia de una misteriosa isla desaparecida en tiempos antiguos, pero cuyo recuerdo aún perdura entre los egipcios. Este carácter mítico e imaginario que envuelve a esa isla llamada Atlántida, situada más allá de los referentes geográficos de la época antigua, parece ejercer un poderoso influjo en Moro. El humanista inglés, al igual que Platón, también se anima a proyectar la existencia de otra isla ubicada fuera de las coordenadas espaciales de la Europa renacentista, el nombre de esta ínsula es Utopía. Cabe aclarar que Platón no es el único autor de la Antigüedad Clásica que evoca lugares o viajes imaginarios que pudieron haber sido fuente de inspiración para Tomás Moro. No obstante, es el filósofo ateniense quien con su «misteriosa» isla Atlántida aporta mayores elementos para la imaginación de una sociedad «perdida».

A parte de los escritos platónicos también existen otras fuentes literarias griegas que pudieron ejercer una fascinación sobre Moro acerca de la existencia de ciertos «lugares» con formas de vida «contraculturales». Así pues, a la obra platónica también podría sumársele las aves de Aristófanes, una comedia a través de la cual el poeta critica a la sociedad ateniense de su época. En esa comedia se narra la historia de dos personajes, Evélpides y Pisteteros, que literalmente huyen de Atenas porque la vida en esa ciudad se había vuelto imposible. Tales fugitivos se lanzan a la búsqueda de una nueva tierra en la que puedan construir otra ciudad. Además de estos autores griegos existen algunas otras fuentes, entre ellas la obra de Luciano de Samósata, que dan cuenta de la cantidad de recursos simbólicos existentes en el mundo clásico griego como antecedentes respecto al contexto literario del cual posiblemente parte Utopía.

A esas fuentes literarias, sobre viajes o lugares imaginarios y sociedades ideales, habría que agregar también otros recursos de carácter filosófico procedentes del ámbito griego. Así, por ejemplo, Mazour-Matusevitch (2014) ha dado cuenta elocuentemente de varios elementos pitagóricos presentes en la obra de Moro. Por su parte, Romano Ribeiro (2014) señala algunas conexiones existentes entre Moro y el De finibus de Cicerón. ${ }^{3}$ En suma, las ideas griegas tienen un papel destacado en el pensamiento de Tomás Moro. ${ }^{4}$ Tal es su he-

${ }^{3}$ En particular, son las ideas estoicas y sobre todo epicúreas que subyacen sobre su visión eudemonista vinculada al placer

${ }^{4}$ Así lo da entender el propio autor en un pasaje específico de su obra: Qui cum a nobis accepissent de litteris et disciplina Graecorum - nam in Latinis praeter historias ac poetas nihil erat quod uidebantur magnopere probaturi- mirum quanto studio contenderunt, ut eas liceret ipsis, nostra interpretatione perdiscere, «Cuando recibieron de nosotros noticia de las letras y de las ciencias griegas (pues no parecían interesarse mucho en las obras de los latinos, excepto en las de los historiadores y poetas), fue cosa admirable ver con qué afán quisieron profundizar en ellas con la ayuda de nuestras explicaciones» (VOLTES, 2002: 91). 
rencia del entorno griego que cuando Moro, en voz de Rafael, hace referencia a las obras de la Antigüedad clásica apreciadas por los utópicos la mayoría de los libros citados son de autores griegos. Entre estas obras griegas, por las cuales los utópicos se interesan, destacan: Platón, Aristóteles, Teofrasto, Homero, Sófocles, Eurípides, Aristófanes, Tucídides, Heródoto, Plutarco, entre otros (VOLTES, 2013: 91-92).

Sin embargo, las ideas griegas no son las únicas que están presentes en la Utopía de Tomás Moro. También es posible rastrear raíces tan remotas como las etiópicas (DEBELE, 2016). De igual forma se pueden hallar elementos procedentes de la tradición de los diálogos renacentistas sobre el texto (MACZELKA, 2014). De todos esos influjos que proceden fuera del ámbito de la tradición clásica griega, la herencia cristiana es uno de los que todavía continúan brindado posibilidades de lecturas alternativas. Entre las aproximaciones realizadas bajo la óptica del trasfondo cristiano se ha indagado acerca de las características de la «religión» que prevalecía entre los utópicos y se le ha comparado con los elementos de la religión cristiana (BOYLE, 2006; NENDZA, 1984). También se ha explorado el vínculo existente entre las prácticas «religiosas» de los utópicos con relación a las prescripciones monásticas de la Orden de los Cartujos (DAVID, 1985). De igual manera, se ha establecido cierta dependencia con la obra de la Ciudad de Dios de San Agustín (BOYLE, 2006).

A pesar de que los estudios anteriores se centran en determinados temas relacionados al cristianismo, lo cierto es que no están necesariamente dedicados al análisis de las fuentes bíblicas como el fundamento que sostiene el proyecto de Utopía. No obstante, también existen otro tipo de estudios que han señalado algunos paralelos entre los textos bíblicos y pasajes específicos de Utopía. Así Braga (2008) muestra cierta correspondencia entre el relato del Edén del Génesis con la ruta de exploración que sigue Rafael Hytlodeo en la obra de Moro. El propio nombre de Rafael parece ser un claro indicio de una referencia al arcángel protagonista del libro bíblico de Tobías (MAZOUR-MATUSEVITCH, 2014). Aun cuando se han realizado estas indagaciones que dan cuenta de la influencia de los textos bíblicos sobre la obra del humanista inglés, siguen prevaleciendo tópicos «cristianos» que pueden ser explorados en la conformación de las ideas que integran el proyecto de los habitantes de Utopía. Son precisamente algunos de esos «otros» elementos cristianos los cuales busca analizar el presente texto.

\section{LA VIDA EN COMÚN: FUNDAMENTO DE UTOPÍA}

Es indudable que Tomás Moro tiene una enorme deuda con la herencia procedente de la tradición clásica griega. No obstante, al revisar cuidadosamente el fundamento mismo de la vida en Utopía, parece surgir algunas ideas esenciales que no se explican solamente a partir del legado clásico. Al final del relato de Utopía hay una precisión respecto a la idea primordial que sostiene todo el proyecto de los habitantes de esa isla legendaria. Aparentemente, dicho fundamento no se localiza en las fuentes griegas clásicas tradicionales, sino que sugiere un contexto eminentemente matizado por los textos fundantes del cristianismo:

Haec ubi Raphael recensuit, quamquam haud pauca mihi succurrebant, quae in eius populi moribus, legibusque perquam absurde uidebantur instituta, non solum de belli gerendi ratione, 
et rebus diuinis, ac religione, aliisque insuper eorum institutis, sed in eo quoque ipso maxime, quod maximum totius institutionis fundamentum est uita scilicet, uictuque communi, sine ullo pecuniae commercio, qua una re funditus euertitur omnis nobilitas, magnificentia, splendor, maiestas, uera ut publica est opinio decora atque ornamenta reipublicae.

Cuando Rafael hubo acabado de hablar, recordé muchos detalles que me habían parecido absurdos en las leyes y costumbres de aquel pueblo, no sólo en la manera de guerrear, su culto e ideas religiosas y las demás instituciones, sino también y más especialmente el fundamento principal de todas ellas: la vida y el patrimonio en común, sin ninguna circulación de moneda, lo cual destruye toda la nobleza, magnificencia, esplendor y majestad que, según la opinión general, constituyen el honor y ornato de las repúblicas. (Cursivas añadidas; VOLTES, 2013: 118)

En esta cita se establece claramente el fundamento sobre el cual la vida en Utopía se sostiene y se organiza: uita scilicet, uictuque communi, «a saber, la vida y el mantenimiento común». Tal idea, según el propio relato, es la que genera todo el proyecto utópico. De ahí que al indagar sobre el origen de esa manera de pensar, se estaría accediendo a la base misma sobre la cual se construye el relato de la Utopía de Moro.

\section{La comunidad de bienes en la Antigüedad Clásica}

Hay en la Antigüedad griega varios autores que podrían citarse como referencia para situar el punto de inicio de esta manera de pensar, Platón podría ser uno de ellos. En el libro VIII de la República, el pensamiento platónico aborda a modo de conclusión el tema de la comunidad de bienes, expuesto en los capítulos precedentes y dice claramente:

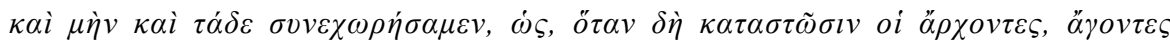

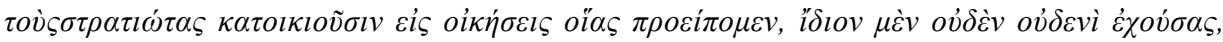

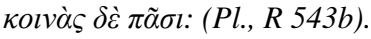

También quedamos de acuerdo en que, una vez puestos en funciones los gobernantes, conducirán a los soldados y los instalarán en moradas tales como las que hemos descrito, no teniendo nada en privado, sino todo en común. (EGGERS LAN, 1986: 378)

Sin embargo, aquí esta vida en común se acota exclusivamente a las clases dirigentes de la república. En caso de Platón la comunidad de bienes no es una exigencia que involucra a la sociedad en su totalidad, como sí sucede en el caso de Utopía. Por consiguiente, a pesar de que la vida en común, se encuentra insinuada de alguna manera en la obra platónica, resulta difícil considerar a este filósofo como el antecedente inspirador de Moro. En la república platónica no se contempla la vida en comunidad y el mantenimiento común como una condición de vida para todos los ciudadanos.

Existe una referencia más sobre la vida común en la Antigüedad griega ubicada en la obra aristotélica. Aunque no se habla estrictamente de la abolición de la propiedad privada se sugiere la igualdad de bienes. En la Política de Aristóteles hay una mención a un tal Fa-

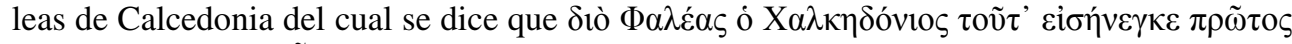

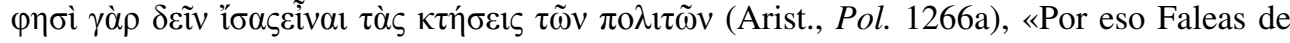


Calcedonia fue el primero que introdujo esta cuestión, al decir que las posesiones de los ciudadanos deben ser iguales» (GARCÍA VALDÉS, 1988: 110-111). Este testimonio que recoge la tradición aristotélica sitúa la vida común y la igualdad como necesarias para evitar las revoluciones, pues el ordenamiento justo de la propiedad entre los ciudadanos es lo más importante y afecta de manera definitiva el rumbo de la ciudad. Incluso, según Aris-

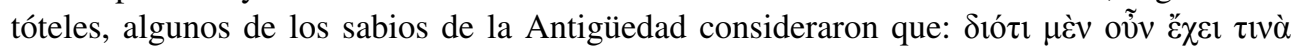

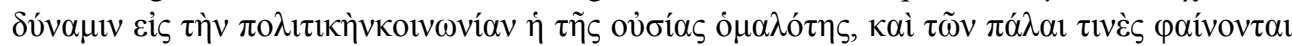
$\delta i \varepsilon \gamma v \omega \kappa o ́ \tau \varepsilon \varsigma$, (Arist., Pol. 1266b), «así pues, la igualdad de la propiedad tiene una evidente influencia en la comunidad política» (GARCÍA VALDÉS, 1988: 111).

Estas referencias aristotélicas parecen sugerir que en la tradición griega clásica se cuenta con la presencia de elementos palpables que promueven la idea y práctica de una distribución igualitaria de bienes, propiedades y riquezas. Sin embargo, el juicio que establece Aristóteles acerca de tales ideas en ningún sentido es favorable. Para este filósofo la estrategia que debiera implementarse en la $\pi$ ó $\lambda$ ı zada por Faleas. Para el pensamiento aristotélico el camino a seguir es diferente: $\mu \tilde{\alpha} \lambda \lambda \mathrm{ov}$

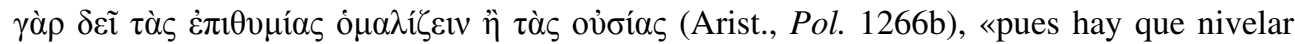
las concupiscencias antes que las fortunas» (GÓMEZ ROBLEDO, 2000: 43). Un poco más

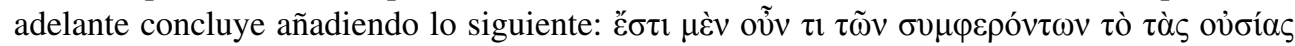

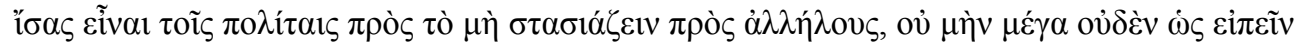
(Arist., Pol. 1267a), «Es, desde luego, una medida conveniente que sean iguales las propiedades de los ciudadanos para que no haya revueltas entre unos y otros, pero no tiene gran importancia, por así decir» (GARCÍA VALDÉS, 1988: 115).

Las citas anteriores de Aristóteles expresan el prejuicio de esa época y dejan entrever claramente la percepción generalizada que tienen los miembros de la élite griega sobre este tema. La perspectiva a la cual se acoge el estagirita ya había sido expuesta de forma contundente por Aristófanes en su comedia Las asambleístas. En dicha obra la idea de concebir una sociedad regida por la comunidad de bienes es una locura cuya ocurrencia solo tiene cabida en la mentalidad de las mujeres. Así Praxágora, la protagonista de esta comedia, es quien pro-

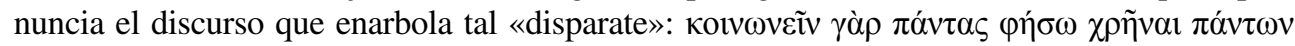

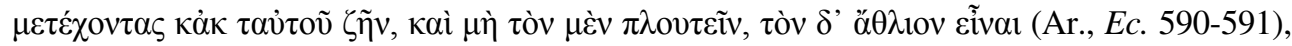
«Os diré que es preciso que sean comunes los bienes de todos, que todos tengan parte del común y vivan de los mismos recursos, y no que uno sea rico pero el otro pobre» (MACÍA APARICIO, 2007: 367). Esa propuesta resulta absurda para la mentalidad griega y, desde luego, Aristóteles tampoco la comparte. Por consiguiente, no resulta pertinente inferir que este haya sido el escenario inspirador para el proyecto utópico de Moro. La idea esencial del proyecto de Utopía tuvo que proceder de otro ambiente cultural y literario.

Así pues, aunque es irrefutable la presencia del legado clásico griego, no es la única vertiente de la Antigüedad Clásica implícita en el pensamiento de Tomás Moro. Esa otra herencia presente en la obra del humanista inglés es, sin duda alguna, la tradición cristiana. Por consiguiente, el cristianismo emerge como otro punto de referencia obligado para leer la tradición clásica implícita en la Utopía de Moro. 


\section{La comunidad de bienes en el trasfondo bíblico}

Para comprender mejor el trasfondo cristiano en el texto de la Utopía es fundamental reconocer las referencias implícitas a la historia de Israel que se encuentran presentes en dicha obra. El pueblo hebreo intentó construir un modelo de organización económico y social diferente a los paradigmas de la época y de las culturas de Canaán. El evento fundacional de la cultura hebrea lo constituyó el éxodo de Egipto. Es aquí donde la fe hebrea descubre los elementos esenciales para imaginar y proyectar un estilo de vida distinto a los regímenes explotadores y opresores de los cuales fueron víctimas. De esta manera, el pueblo de Israel se establece como un proyecto social alternativo a los sistemas opresores del mundo antiguo, los cuales solo buscan acumular riquezas y bienes a costa de una organización injusta y opresora (PIXLEY, 1986: 21-31). Mediante la creación de una sociedad en la cual la distribución de la riqueza sea repartida equitativamente, según las necesidades de cada quien, Israel pretende separarse de las visiones distorsionadas de la sociedad basadas en relaciones de explotación; a cambio, propone un escenario donde todos tengan la posibilidad de cubrir sus necesidades por igual. El libro de Éxodo narra la historia de estas ideas así como las dificultades que enfrentó el pueblo en su búsqueda de una «tierra prometida». Al respecto hay un pasaje sumamente interesante que describe el ideal anhelado por este nuevo pueblo. De la misma manera, tal narración bíblica muestra a la vez de forma explícita el criterio de la igualdad de bienes aplicado a un proyecto comunitario. Al abordar el tema del maná el texto bíblico dice:

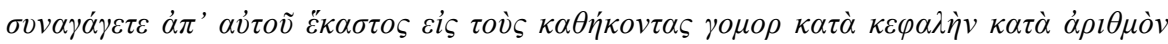

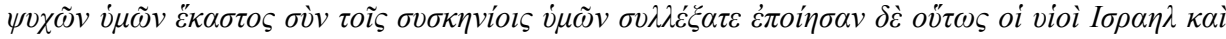

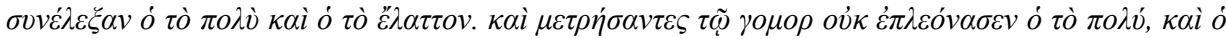

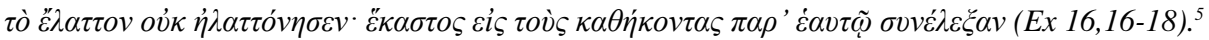

Recoged de los que hay cada uno para los que estén debajo de su tutela: un gómor por cabeza, según el número de personas a vuestro cargo; recogedlo cada uno con vuestros compañeros de tienda. Hicieron así los hijos de Israel, y recogieron, uno mucho y otro menos. Y lo midieron con un gómor; no estuvo sobrado el de mucho ni el de menos se quedó corto; cada uno recogió para los que estaban bajo su tutela. (FERNÁNDEZ MARCOS-SPOTTORNO DÍAZCARO, 2008: 183)

El criterio que se impone en la narración bíblica es una distribución igualitaria de los bienes con el fin de suplir las necesidades de manera equitativa. Este criterio para la repartición de los recursos no queda únicamente en la historia antigua de Israel; por el contrario, se recupera en la organización inicial del cristianismo primitivo. Pablo de Tarso lo retoma para definir el tipo de relaciones que deben prevalecer en la nueva comunidad cristiana con referencia a los bienes y riquezas:

\footnotetext{
${ }^{5}$ Se emplea el texto de los LXX por el hecho de que se está tratando de establecer el trasfondo cristiano que subyace en la obra de Moro. Ha quedado claro que el texto del AT utilizado por los primeros cristianos fue la Biblia griega y no la hebrea (FERNÁNDEZ MARCOS, 2000, 2008). Por esta causa, si se desea acceder al sentido que el AT tuvo para los primeros cristianos es necesario recurrir a la versión de los LXX.
} 


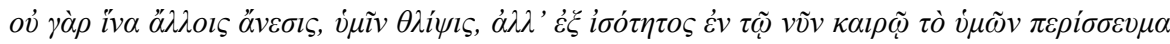

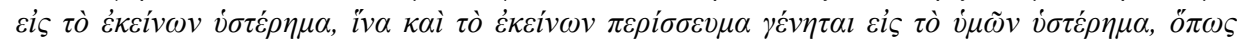

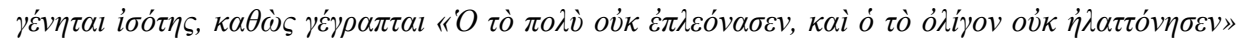
(2 $\operatorname{Cor} 8,13-15)^{6}$

No que paséis apuros para que otros tengan abundancia, sino con igualdad. Al presente, vuestra abundancia remedia su necesidad, para que la abundancia de ellos pueda remediar también vuestra necesidad y reine la igualdad, como dice la Escritura: El que mucho recogió, no tuvo de más; y el que poco, no tuvo de menos. (CANTERA-IGLESIAS)

Así el cristianismo primitivo asume la tarea, como anteriormente lo había hecho el antiguo Israel, de formar una comunidad alternativa ante la desigualdad imperante ahora en la sociedad romana. El libro de Hechos recoge de modo muy específico la manera en cómo se concretó el ideal de la igualdad a través de la comunidad de bienes entre los primeros cristianos. Son varios los textos bíblicos que describen la vida de las primeras comunidades en torno a este principio que ya había sido enunciado desde el AT: $\pi \alpha ́ v \tau \varepsilon \zeta \delta \varepsilon \grave{\varepsilon}$ oi

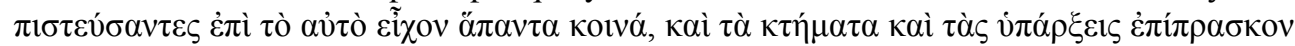

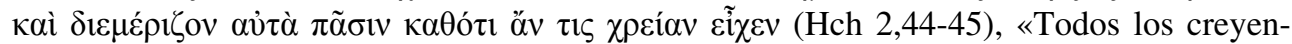
tes vivían unidos y tenían todo en común; vendían sus posesiones y sus bienes y repartían el precio entre todos, según la necesidad de cada uno» (CANTERA-IGLESIAS). Más adelante en este mismo libro hay dos referencias similares:

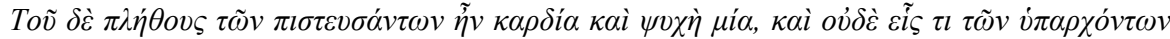

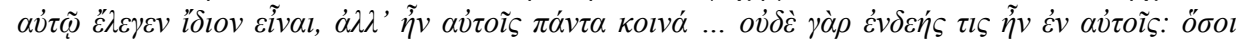

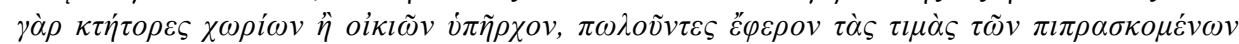
(Hch 4,32.34).

La multitud de los creyentes no tenía sino un solo corazón y una sola alma. Nadie llamaba suyos a sus bienes, sino que todo era en común entre ellos ... No había entre ellos ningún necesitado, porque todos los que poseían campos o casas los vendían, traían el importe de la venta (CANTERA-IGLESIAS).

\section{Comparación entre los textos bíblicos y el texto de Utopía}

La concordancia de estas narraciones bíblicas con los relatos sobre la vida en Utopía resulta estrecha. Como ya ha sido señalado, al parecer este ideal no se encuentra desarrollado claramente en ningún otro espacio literario de la Antigüedad griega o helenística, a excepción de los pasajes narrados en Hechos. Así pues, los ecos de estos textos en la obra de Tomás Moro son indiscutibles. Hay varios pasajes que, al ser leídos de modo paralelo, ejemplifican la relación entre el libro de Hechos y Utopía.

${ }^{6}$ Para el texto griego del NT se utiliza: ALAND, B. y K; KARAVIDOPOULOS, J.; MARTINI, C.M y METZGER B.M. (eds.) (2012): Novum Testamentum Graece, (28th Revised Edition), Stuttgart: Deutsche Bibelgesellschaft. 
En primer lugar, persiste en ambas obras la idea de la supresión o abolición de la propiedad privada en contraste con la vida común que pone fin a la acumulación desenfrenada de bienes. De manera concreta Moro escribe al respecto:

Quod si aut ea dicerem, quae fingit Plato in sua republica aut ea quae faciunt Utopienses in sua, haec quamquam essent, ut certe sunt, meliora, tamen aliena uideri possint, quod hic singulorum priuatae sunt possessiones, illic omnia sunt communia.

Suponed que les explicase lo que finge Platón en su República, o lo que está en vigor entre los utópicos; lo cual, aunque fuese, como es, mejor que lo nuestro, a ellos les parecería fuera de lugar, como, por ejemplo, que aquí domine el régimen de la propiedad privada, mientras que allí todas las cosas son comunes. (VOLTES, 2013: 58)

En el texto anterior, por una parte, se aprecia claramente que el autor está abordando el tema de la comunidad de bienes (omnia sunt communia) en la sociedad de Utopía. Por la otra, a pesar de que Moro reconoce que es una temática presente en la República de Platón, la filosofía griega no la desarrolla de manera concreta como los pobladores de Utopía. Platón solo «finge» esa realidad. De esta manera, la comunidad cristiana primitiva en la cual

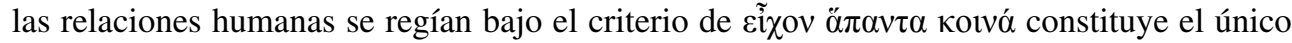
paralelo real respecto a la comunidad de bienes que prevalecía en Utopía donde omnia sunt communia. Así tanto los utópicos como los cristianos primitivos poseían el mismo referente de organización en torno a las posesiones materiales.

En segundo, la idea de igualdad parece ser el principio que regula la organización social. Por consiguiente, se deja de lado las relaciones jerárquicas que surgen a partir de la posesión privada de las riquezas. De acuerdo con Moro, la renuncia a las posesiones personales es condición necesaria para alcanzar la comunidad de bienes, tal y como lo afirma en las siguientes palabras:

Siquidem facile praeuidit homo prudentissimus, unam atque unicam illam esse uiam ad salutem publicam, si rerum indicator aequalitas, quae nescio an umquam possit obseruari, ubi sua sunt singulorum propria.

Aquel varón prudentísimo preveía claramente que el único medio de salvar a un pueblo es la igualdad de bienes, cosa que no sé cómo pueda obtenerse mientras exista la propiedad privada. (VOLTES, 2013: 60)

Sin duda, detrás de estas ideas resuena el eco de la comunidad de bienes del libro de $\mathrm{He}$ chos. Según el relato bíblico, en la iglesia primitiva no existía tampoco la propiedad privada

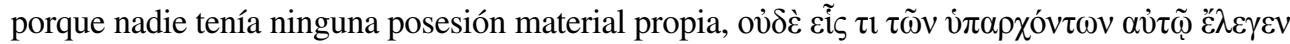
íoıv cĩvol. La fuente de inspiración para la descripción de la vida en Utopía una vez más procede de la tradición bíblica y no del ambiente literario o filosófico griego. A pesar de que se alude explícitamente a Platón en el texto, con la frase homo prudentissimus, lo cierto es que el filósofo ateniense solo «finge» la ausencia de la propiedad privada; mientras que, en la comunidad cristiana de Jerusalén la posesión comunitaria de los bienes se lleva a la práctica.

Tercero, en Utopía la distribución de los bienes comunitarios con base en las necesidades sociales es una realidad que permite una vida armónica, segura y libre de pobreza. Al 
respecto, se dice lo siguiente acerca de la forma de vida de los utópicos: contra hic, ubi omnia omnium sunt nemo dubitat ... nihil quicquam priuati cuiquam defuturum, «Por el contrario, en Utopía, donde todo es de todos, nadie teme que pueda faltarle en lo futuro nada personal» (VOLTES, 2013: 115). Esta es la misma idea que se localiza en Ex 16,18 y que posteriormente Pablo de Tarso retoma en 2 Cor 8,13-15. La norma de igualdad, tanto en Utopía como en las fuentes bíblicas, tiene la misma intención, que «nadie padezca necesidad». Este último punto es uno de los rasgos esenciales de la forma de vida, tanto en el Israel antiguo, como en las primeras comunidades cristianas. En ambos proyectos bíblicos se enfatiza el canon de la necesidad para la distribución de los bienes. Considerar este criterio, «según la necesidad», abre la posibilidad de establecer un vínculo más entre el pensamiento del cristianismo primitivo y la Utopía de Moro.

Finalmente, Moro parece coincidir con la tradición bíblica respecto a las consecuencias devastadoras que tiene la acumulación de bienes para la vida en comunidad. En el pasaje ya referido al libro de Éxodo se emplea una metáfora fascinante para describir lo que sucede con aquel que se resiste a la igualdad como base para solventar las necesidades. El relato bíblico describe los inconvenientes de no ajustarse al paradigma de la «necesidad»: $\varepsilon \tilde{i} \pi \varepsilon v$

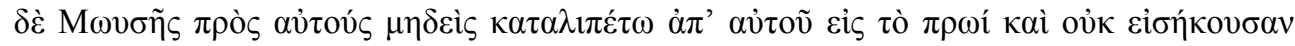

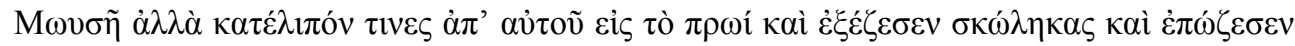
(Ex 16,19-20), «Y les dijo Moisés: «Nadie deje nada para el día siguiente», y no hicieron caso a Moisés, sino que algunos dejaron algo para el día siguiente; y crió gusanos y apestó» (FERNÁNDEZ MARCOS-SPOTTORNO DÍAZ-CARO, 2008:183).

Este es el juicio de la tradición bíblica frente a la acumulación absurda de los bienes. Juntar recursos sin un propósito comunitario es algo ilógico y torpe, pues ello implica un riesgo para la vida comunitaria. Quien piensa únicamente en acaparar termina generando «gusanos y pestilencia». Al parecer Moro lo entendió de manera similar y por ello escribe lo siguiente: mihi uidetur ubicumque priuatae sunt possessiones, ubi omnes omnia pecuniis metiuntur, ibi uix umquam posse fieri, ut cum republica aut iuste agatur, aut prospere, «dondequiera que exista la propiedad privada, donde se midan todas las cosas por el dinero, apenas se podrá conseguir que el Estado se rija equitativa y prósperamente» (VOLTES, 2013: 59).

\section{DE LA COMUNIDAD DE BIENES A UNA NUEVA CIUDAD: LA FUERZA DEL PROFETISMO Y DE LA APOCALÍPTIC}

A partir de la descripción que ofrece el libro de los Hechos de esta nueva comunidad, el cristianismo primitivo comienza a visualizar, evocar y proyectar una imagen utópica de lo que debiera ser la Iglesia. Es pues necesario seguir buscando en las ideas cristianas los elementos fundantes de la vida en Utopía que la tradición clásica griega no parece desarrollar completamente y, no obstante, son esenciales para interpretar la comunidad de bienes en la obra de Moro. Este otro sitio de indagación, dentro del cauce de la tradición cristiana puede constituirlo la imaginación de la literatura profética y la protesta de la escritura apocalíptica.

Desafortunadamente suele ser común interpretar tanto el profetismo como el género apocalíptico de manera literal, situación que da origen a una incomprensión total de sus figuras e imágenes. El discurso profético al igual que el apocalíptico puede proporcionar, 
símbolos, imágenes, lugares, figuras e historias, que alimentan la narrativa utópica. En general el contexto económico, político y cultural del profetismo, y en específico de la apocalíptica, está delimitado por la desintegración, persecución, opresión permanente y, sobre todo, por una exclusión creciente (RICHARD, 1995: 40-41). El contexto narrativo del profetismo y de la apocalíptica es muy similar a la lectura de la sociedad inglesa que se plantea Moro en la Utopía. La Inglaterra del siglo XVI se ubica en la transición entre un sistema feudal y el naciente capitalismo; ello trae como consecuencia, producto de esta transformación económica, una forma de vida distinta que solo estaba generando mayor pobreza, desigualdad y, por supuesto, exclusión:

ibi nobiles et generosi, atque adeo Abbates aliquot sancti uiri, non his contenti reditibus, fructibusque annuis, qui maioribus suis solebant ex praediis crescere, nec habentes satis, quod otiose ac laute uiuentes, nihil in publicum prosint, nisi etiam obsint, aruo nihil relinquunt, onmia claudunt pascuis, demoliuntur domos, diruunt oppida, templo dumtaxat stabulandis ouibus relicto, et tamquam parum soli perderent apud uos ferarum saltus, ac uiuaria, illi boni uiri habitationes omnes, et quicquid usquam est culti, uertunt in solitudinem. Ergo ut unus helluo inexplebilis ac dira pestis patriae, continuatis agris, aliquot milia ingerum uno circumdet septo, eiiciuntur coloni. quidam suis etiam aut circumscripti fraude, aut ui oppressi exuuntur, aut fatigati iniuriis, adiguntur ad uenditionem.

los señores, los caballeros y aun los abades, algunos santos varones, no se contentan con las rentas y beneficios que sus antecesores solían obtener de sus dominios e, insatisfechos con poder vivir muelle y perezosamente, sin ser en manera alguna útiles a la sociedad, antes bien nocivos, no dejan ninguna parcela para el cultivo; todo se cierra para pastos, derriban las casas, destruyen los pueblos; y si respetan las iglesias, es porque sirven de establos a sus ovejas. Y como si no se perdiera poca tierra en dehesas y cotos, aquellos excelentes varones transforman en desiertos las viviendas y todo lo cultivado. Así, pues, para que un devorador insaciable, peste y plaga de su patria, pueda encerrar en un solo cercado varios millares de yugadas de tierras, muchos campesinos se ven privados de sus bienes, los unos por fraude; otros, expulsados violentamente o que, hartos ya de tantas vejaciones, se ven obligados a vender lo que poseen. (VOLTES, 2013: 42-43)

Una situación como la anteriormente descrita es un escenario que sin duda despierta la imaginación profética (BRUEGGEMANN, 1986) y conduce a la búsqueda de figuras, imágenes o mitos que sean capaces de evocar un escenario distinto. De manera habitual se ha entendido al profeta dentro de la tradición cristiana como una especie de adivino de eventos futuros regularmente catastróficos; sin embargo, dentro del marco teológico esta actividad tiene una función bien definida. Así, la tarea esencial del profetismo bíblico consiste «en propiciar, alimentar y evocar una conciencia y una percepción de la realidad alternativas a las del entorno cultural dominante» (BRUEGGEMANN, 1986: 12). ${ }^{7}$ Por consiguiente,

\footnotetext{
7 Walter Brueggemann al presentar esta definición reconoce en una nota de pie al margen que «Esta formulación esta formalmente inspirada en la sociología de Peter L. BERGER y Thomas LUCKMANN, La construcción social de la realidad, Ed. Amorrortu, Buenos Aires 1979 (5ta ed.); Peter L. BERGER, El dosel sagrado. Elementos para una sociología de la religión, Ed. Amorrortu, Buenos Aires 1971; Thomas LUKCMANN, La religión invisible, Ed. Sígueme, Salamanca 1973. Ahora bien, lo que nosotros nos interesa es la sustancia del ministerio profético, y no simplemente la elaboración formas. En este sentido, el tema ha sido perfectamente expuesto por Douglas HALL, Lighten Our Darkness, Westminster Press, Filadelfia 1976».
} 
tanto los textos bíblicos como la función profética, desde esta última aproximación, adquieren un nuevo sentido, puesto que «En toda la Biblia es fundamental el tema de la esperanza y utopía. El espíritu de toda la tradición bíblica es búsqueda de un mundo nuevo y trascedente» (RICHARD, 1995: 268). Aquí «trascendente» hay que entenderlo desde el significado literal que refiere, «lo que está por encima»; es decir, remite al ámbito de la imaginación utópica.

El cristianismo primitivo no concibe a esta nueva comunidad trascendente como una entidad segregada socialmente. Antes bien, la considera como parte del inicio de una nueva ciudadanía perteneciente a un entorno social con características totalmente distintas a las otras urbes históricas. Es por esta razón que las relaciones existentes hacia el interior de la nueva comunidad, la nueva ciudad, la iglesia, deben estar regidas por una dinámica di-

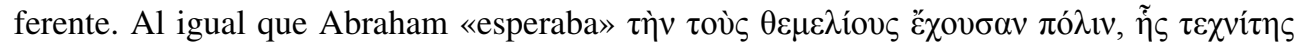

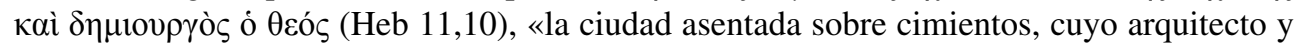
constructor es Dios»(CANTERA-IGLESIAS), los cristianos primitivos continúan en esa misma espera y son capaces de visualizar una modalidad de urbanización diferente a las existentes en el ambiente grecorromano.

Sin embargo, esa ciudad para los cristianos primitivos no es una entidad alejada totalmente en el futuro, sino una realidad escatológica que se comienza a materializar en la iglesia. En otro pasaje, dentro de la misma epístola a los Hebreos, se les dice de manera precisa a los cristianos:

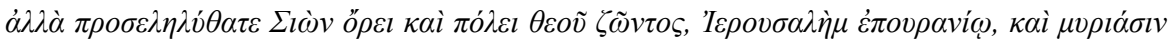

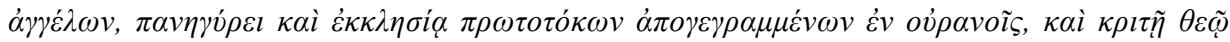

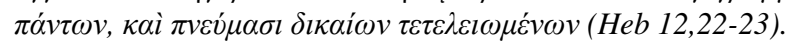

Vosotros, en cambio, os habéis acercado al monte de Sión, a la ciudad de Dios vivo, la Jerusalén celestial, y a miríadas de ángeles, reunión solemne y asamblea de los primogénitos inscritos en los cielos, y a Dios, juez universal, y a los espíritus de los justos llegados ya a su comunión. (CANTERA-IGLESIAS)

El paralelismo sinónimo que subyace en la construcción de esta referencia neotes-

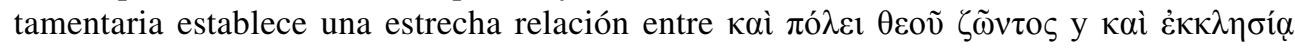

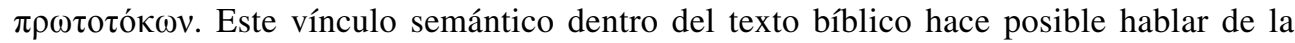
ciudad de Dios como sinónimo de la Iglesia. Es obvio, que la referencia bíblica no alude a la institución eclesiástica de la época de Moro, la cual pretendía ubicar su sede en Roma; sino a esa nueva realidad social que se iba gestando en las comunidades cristianas primitivas con características muy diferentes a la Inglaterra en la cual el humanista inglés vivió.

Ahora bien, la tradición griega clásica posiciona a Hipodamo (Arist., Pol. 1267b-1268a) como uno de los urbanistas utópicos iniciales (TROUSSON, 1995: 75). Sin embargo, no es el único ni el primero que habla del trazo ideal de alguna ciudad o algún edificio de manera utópica. En la narración bíblica, «la utopía de una nueva Jerusalén tiene una larga tradición» (RICHARD, 1995: 269), la cual es retomada por la imaginación profética y más tarde por la esperanza apocalíptica. La visión de una nueva ciudad, de una nueva 
Jerusalén, comienza a vislumbrarse desde el año 586 a. de C. con Jeremías. ${ }^{8}$ Una vez que la Jerusalén «histórica» fue derribada por el ejército de Babilonia la imaginación profética fue

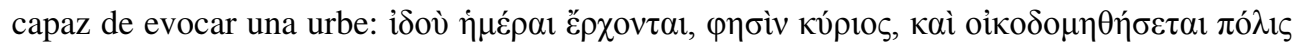

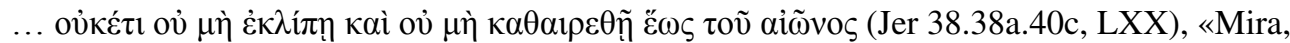
vienen días, dice el Señor, y será construida una ciudad ... Ya no desaparecerá y ya no se derribará, por siempre» (FERNÁNDEZ MARCOS-SPOTTORNO DÍAZ-CARO, 2015: 300). En este mismo pasaje se comienza a perfilar cuál será el trazo ideal de la nueva ciudad. Algo similar ocurre durante la cautividad que experimenta el pueblo de Israel en Babilonia. En el transcurso del exilio babilónico la voz profética sigue vigente a través de la resistencia encabezada por Ezequiel ${ }^{9}$ y el Deutero-Isaías. ${ }^{10}$ Ambos profetas nuevamente, con fuerte sentido utópico, evocan figuras, imágenes y símbolos de la nueva Jerusalén a un pueblo cuyo futuro está en riesgo. Al término de la cautividad en Babilonia, y tras el posterior regreso del pueblo de Israel a Jerusalén, la nueva ciudad adquiere una dimensión mítica con carácter apocalíptico. Ahora esa «ciudad mítica» proyecta las aspiraciones y anhelos de una sociedad que busca la redefinición de su identidad avasallada por la conquista.

En el caso del único apocalipsis canónico de procedencia cristiana, la imagen de la Jerusalén celestial, la ciudad de Dios, se convierte en una poderosa figura que es capaz de encarnar los ideales de cualquier proyecto utópico. Toda la herencia de la tradición bíblica anterior se ve materializada en la descripción física que se hace de la nueva Jerusalén en Apocalipsis 21,9-27. Aquí en este relato se muestran las características, materiales, dimensiones y trazo «urbanístico» de la nueva urbe. La narración del escritor apocalíptico «utiliza este modelo de reconstrucción de una ciudad, como instrumento para la reconstrucción de la esperanza, de la utopía, del proyecto trascendente y escatológico de Dios para con toda la humanidad» (RICHARD, 1995: 263). Así, considerar que la Jerusalén celestial es una realidad a la que se accede de manera pasiva mediante la provisión divina implica restarle fuerza a la proyección apocalíptica en su posibilidad de evocar escenarios diferentes.

El influjo de toda esta tradición apocalíptica se verá reflejado de manera explícita en la obra de Moro a través de la percepción que lo utópicos tienen sobre las riquezas y el valor que le otorgan al oro en esa isla. De modo preciso, cuando Rafael describe la vida de aquellos habitantes de esa tierra legendaria, señala que: Ex auro, atque argento non in communibus aulis modo, sed in priuatis etiam domibus, matellas passim, ac sordidissima quaeque uasa conficiunt, «el oro y la plata sirven, no sólo en los edificios comunes, sino en las casas particulares, para hacer vasos de noche y recipientes destinados a los usos más innobles» (VOLTES, 2013: 80). Con ello no se deja lugar para la duda sobre el uso innoble

8 Jer 37,1-12 conforme a los LXX. Para el texto hebreo consultar Jer 30,1-12.

${ }^{9}$ Ezequiel, capítulos 47-48.

${ }^{10}$ De acuerdo con los estudios de la crítica literaria, los exégetas distinguen en la obra del Isaías canónico a por lo menos tres autores diferentes, ubicados en tres momentos distintos de la historia de Israel. El primero de ellos se le conoce, como el primer Isaías o Isaías de Jerusalén y su obra se le vincula con el personaje histórico que vivió durante el siglo viII a. de C. A Este autor se le atribuyen la autoría de los capítulos 1 al 39. El segundo autor se le conoce como el Deutero Isaías, a él se le ubica durante el exilio en Babilonia y se le adjudica la obra de los capítulos 40 al 55. Finalmente, los capítulos restantes, 56 al 66, se le atribuyen a un personaje que debió haber escrito una vez que el pueblo de Israel regresara de la cautividad babilónica a Jerusalén. 
que se le asigna al supuesto bien más preciado, el oro. Este mismo uso vil del oro aparece en la narración apocalíptica cuando se describen las características de la nueva Jerusa-



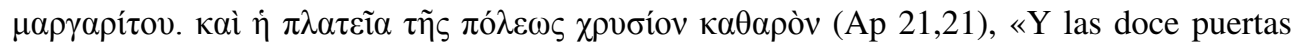
son doce perlas, cada una de las puertas hechas de una sola perla; y plaza [calle] de la ciudad es de oro puro» (CANTERA-IGLESIAS). Así como en Utopía el oro y la plata no tenían el uso «noble» que habitualmente se les confiere, también en la nueva Jerusalén el oro y las perlas son un simple material de construcción. Además, en ambas ciudades el metal dorado tiene una función vil, pues en la nueva ciudad de Jerusalén el oro es empleado para la fabricación de las calles; es decir, para ser pisado y hollado por los ciudadanos de aquella urbe, «ya no sirve para nada, sino para que la gente la deseche y la pisotee» (Cf. Mt 5,13, en un paralelismo parafraseado con de otro bien preciado en la antigüiedad, la sal).

\section{IMPLICACIONES DEL PENSAMIENTO UTÓPICO DESDE LA TRADICIÓN CRISTIANA}

Situar el trasfondo cristiano en la Utopía de Moro implica y obliga, a la vez, a pensar y resignificar el concepto de lo utópico. Trousson (1995: 70-71) parece suponer que la utopía únicamente es concebible a partir de una visión cíclica del tiempo donde la idea del eterno retorno es la que la alimenta posibilidad de encontrarse con un mundo mejor perdido en el acontecer del tiempo. Por el contrario, se afirma que el judeocristianismo construye su discurso sobre una concepción del tiempo lineal donde únicamente queda esperar el final de los tiempos para que se presente la reconstrucción escatológica.

Esta idea de Tousson es sumamente debatible. En principio, aunque generalmente el cristianismo mantiene una visión lineal del tiempo, hay varios desarrollos teológicos que implican una noción del tiempo de manera distinta. Un claro ejemplo, de que no toda la temporalidad bíblica es lineal, lo constituye el pensamiento mítico que circunda a toda la tradición cristiana acerca del «paraíso perdido». A partir de la caída adámica y tras su expulsión del paraíso, toda la historia del ser humano es un «intento» por regresar al huerto del Edén del que fue despojado. Las imágenes apocalípticas están plagadas de este tipo de referencias, una muestra de ello es el símbolo del árbol de la vida que se ubica en medio del paraíso. Este mismo árbol figura como recompensa a los que venzan durante el periodo de tribulación que se abate sobre ellos (Ap 2,7). De igual modo, en la nueva ciudad, la nueva Jerusalén, que surge hacia el final de libro de Apocalipsis (Ap 22,2), contiene en su interior ese mismo árbol de la vida del cual se alimentarán sus ciudadanos y las naciones. Existe pues la idea de volver al inicio, al primer amor (Ap 2,4), a la situación inicial, es decir, retornar al punto de partida.

En segundo lugar, por qué se tiene que pensar que únicamente desde una visión cíclica del tiempo es posible concebir un discurso utópico. Esta manera de proceder parece contemplar únicamente el origen del pensamiento utópico dentro de la cultura griega; de manera que, para que una utopía pueda ser considerada como tal debe necesariamente sufrir un proceso de «helenización». Sin embargo, como se ha tratado de precisar en este lugar, la cultura griega no es la única en desarrollar ideas e imágenes utópicas. Ante este hecho solo quedan dos caminos, o se heleniza totalmente el tiempo bíblico para hacerlo compatible con 
la idea del eterno retorno, que sería ir en la dirección de lo expuesto en el párrafo anterior; o bien, se abre el horizonte temporal desde el cual se construye la utopía para así dar cabida a la temporalidad cristiana.

Es esta segunda opción ofrece mejores resultados porque hace coincidir la noción de utopía con una vertiente eminentemente social. Al respecto Marcuse ha señalado que «el concepto de utopía es un concepto histórico. Se refiere a los proyectos de transformación social que se consideran imposibles» (MARCUSE, 1986: 8). Esa es la historicidad que hay que rescatar en el concepto de utopía, el cual presupone más una dimensión lineal del tiempo. Desde esta concepción «lineal» el ser humano está obligado a pensar un escenario diferente; la fatalidad cíclica inmoviliza, pues el curso de los tiempos recuperará, a su debido momento, lo perdido. En cambio, una visión del tiempo distinta a la cíclica, favorece realmente un pensamiento utópico, pues el futuro se presenta como un escenario por construir y siempre está latente la expectativa del «porvenir».

Hoy más que nunca existe la necesidad de recobrar la imaginación utópica con la cual Tomás Moro nos confronta. No obstante, el escenario filosófico suele proclamar el fin de la historia, de las utopías y de los metarrelatos. En este final de la utopía,

- esto es, la refutación de las ideas y las teorías que han utilizado la utopía como denuncia de posibilidades histórico-sociales - se puede entender ahora, en un sentido muy preciso, como final de la historia, (...) en el sentido de que las nuevas posibilidades de una sociedad humana y de su mundo circundante no son ya imaginables como continuación de las viejas, no se pueden representar en el mismo continuo histórico (MARCUSE, 1986: 7).

\section{CONCLUSIÓN}

A lo largo de este escrito se han señalado algunos elementos que pudieron servir como fuente de inspiración para que Tomás Moro escribiera su obra. De ninguna manera se niega la abundante presencia de elementos procedentes de la cultura griega clásica, pero sí se sugiere que no son suficientes para explicar el origen de algunas ideas utilizadas por Moro. Una de estas ideas que no explica cabalmente el contexto de la Antigüedad clásica, a través del legado griego, es el mismo fundamento que sostiene toda la vida en Utopía: la vida en común. La cultura griega no desarrolla plenamente este rasgo concreto de la organización social utópica. Aunque, sin duda, este elemento fundamental para la conformación del proyecto comunitario de Utopía se encuentra insinuado en los escritos de algunos pensadores griegos, es en la tradición cristiana donde cobra verdadero realce y significado. De ahí que para abordar las fuentes literarias que pudieron dar origen al relato de Utopía es necesario recurrir también al trasfondo judeocristiano. En este sentido la herencia cristiana constituye un sitio más donde la Antigüedad permanece viva con la capacidad de aportar narrativas para la labor intelectual de Moro. Por esta razón, resulta factible considerar al texto bíblico como una fuente determinante que inspiró el núcleo argumentativo bajo el cual el humanista inglés escribió esta obra.

Por lo anterior, se puede sostener que la influencia cristiana sobre la obra de Moro no radica solo en las ideas y en la tradición cultural del cristianismo; sino que reside también 
en la incorporación misma del texto bíblico como fuente literaria. Sin lugar a dudas la presencia de elementos cristianos en la Utopía de Moro ha sido plenamente atestiguada por diversos estudios que dan cuenta de ello. No obstante, también es necesario apuntalar que el texto bíblico fue una fuente importante para la premisa primordial que sostiene el proyecto comunitario de Utopía. En este sentido son varios los cauces desde el trasfondo cristiano bíblico que alimentan el pensamiento utópico del humanista. En principio, está la noción de la igualdad de bienes distribuidos sobre la base de la necesidad que conduce a la erradicación de la propiedad privada. Segundo, el texto bíblico también aporta figuras, símbolos e imágenes, así como la evocación de una ciudad-república perfecta, donde existe un trastrocamiento de los valores convencionales. Moro encuentra en la tradición textual del cristianismo todo un universo simbólico que la tradición judeocristiana había venido desarrollando de manera paralela a las ideas griegas. Por último, el contexto histórico social, desde el cual emergieron los referentes utópicos de la tradición judeocristiana, mantiene un estrecho paralelo con el entorno social de la Inglaterra de Moro.

Finalmente, solo resta decir que toda esta «carga» bíblica textual es una fuente de inspiración con la capacidad de alentar la imaginación profética, no únicamente de Tomás Moro, sino de cualquiera. No obstante, el texto bíblico ha conducido a una cantidad innumerable de proyectos «históricos» de diversa índole. Así se ha encontrado en las páginas bíblicas la «justificación textual» para toda una serie de prácticas que promueven la guerra, el odio y la exclusión. Sin embargo, también la Biblia puede propiciar proyectos alternativos de igualdad y justicia. Es responsabilidad de cada época reflexionar acerca de cómo lee el texto bíblico y con qué propósito se aproxima al mismo. Tomás Moro encuentra en la lectura de Biblia las imágenes y símbolos que le permiten construir un escenario alternativo a la sociedad de su tiempo. Nuestro contexto necesita más de ese tipo de lecturas que evoquen realidades sociales alternativas donde la equidad y la diversidad sean el punto de referencia para la construcción de una sociedad diferente, Así pues, por una parte, se requieren más lecturas que surjan de esa imaginación profética y, por la otra, se necesitan menos lecturas fundamentalistas que solo alientan la descalificación y el prejuicio.

\section{BIBLIOGRAFÍA}

Aland, B. y K; Karavidopoulos, J.; Martini, C.M. y Metzger B.M. (eds.) (2012). Novum Testamentum Graece (28 ${ }^{\text {th }}$ Revised Edition), Stuttgart: Deutsche Bibelgesellschaft.

Braga, Corin (2008). «L'Eden Biblique et l'Utopie de Thomas More», Philologica Jassyensia, 4/1, pp. 83-88.

Brueggemann, Walter (i986). La imaginación profética, Santander, Sal Terrae.

Boyle, John (2006). «Theological Designs: Religion in Utopia», Thomas More Studies I, pp. 68-71.

Burnet, John (ed.) (I903). Plato. Platonis Opera, Oxford, Clarendon.

Cantera Burgos, Francisco-Iglesias González, Manuel (2003). Sagrada Biblia. Versión crítica sobre los textos hebreo, arameo y griego, Madrid, BAC.

Corrigan, Kevin (I990). «The Function of the Ideal in Plato's Republic and St. Thomas More's Utopia», Moreana, 37/104, pp. 27-49.

DAvid, J.C. (1985). Utopía y la sociedad ideal: estudio de la literatura utópica inglesa, 1516-1700, México, D.F.: Fondo de Cultura Económica. 
Debele, Meskerem (2016). «The Ethiopian root of Thomas More's Utopia», International Journal of African Renaissance Studies - Multi-, Inter-and Transdisciplinarity, 11/1, pp. 22-33.

Eggers Lan, Conrado (ed. y tr.) (I986). Platón diálogos IV. República, Madrid, Gredos.

Fernández Marcos, Natalio (2000). The Septuagint in Context. Introduction to the Greek Version of the Bible, Leiden, Brill.

Fernández Marcos, Natalio (2008). Septuaginta. La Biblia griega de judios y cristianos, Salamanca, Sígueme.

Fernández Marcos, Natalio-Spottorno Díaz-Caro, María Victoria (coords.) (2008). La Biblia griega Septuaginta I. Pentateuco, Salamanca, Sígueme.

Fernández Marcos, Natalio-Spottorno Díaz-Caro, María Victoria (coords.) (20I5). La Biblia griega Septuaginta IV. Libros históricos, Salamanca, Sígueme.

García Valdés, Manuela (ed. y tr.) (i988). Aristóteles. Política, Madrid, Gredos.

Gómez Robledo, Antonio (ed. y tr.) (200o). Aristóteles. Política, México, UNAM.

Hall, W.f.-Geldart, M.W. (eds.) (I907). Aristophanes. Aristophanes Comoediae, Oxford, Clarendon Press.

Logan, M. George; Adams, M. Robert and Miller, H. Clarence (eds.) (2006). Thomas More. Utopia. Latin Text and English Translation, Cambridge, University Press.

Macía Aparicio, Luis (ed. y tr.) (2007). Aristófanes comedias III: Lisístrata, las tesmoforias, las ranas, la asamblea de las mujeres, Pluto, Madrid, Gredos.

Marcuse, Herbert ( 1986). El final de la utopía, Barcelona, Ariel.

Marc'Hadour, Germain (I969-I97I). The Bible in the Works of St. Thomas More, 5 Vols., Nieuwkoop: B. de Graaf,

Maczelka, Csaba (20I4). «Sermo, Colloquium, Decorum: The Dialogic Root of Sir Thomas More's Utopia», ANQ: A Quarterly Journal of Shorts Articles, Notes, and Reviews, 27/3, pp. 97-104.

Mazour-Matusevitch, Yelena (20I4). «(Neo) Pythagorean Visión in Thomas More's Utopia», Moreana, 51/195-196, pp. 85-102.

Nendza, James (I984). «Religion and Republicanism in More's Utopia», The Western Political Quarterly, Vol. 37, No. 2, pp. 195-211.

Pixley, JoRge (1986). Biblia y liberación de los pobres. Ensayos de Teología Bíblica Latinoamericana, México, CAM.

Rahlfs, Alfred-Hanhart, Robert (eds.) (2006). Septuaginta, Stuttgart, Deutsche Bibelgesellschaft. Richard, PABlo (1995). Apocalipsis. Reconstrucción de la esperanza, México, Dabar.

Romano Ribeiro, Ana Claudia (20I4). «Intertexual connections between Thomas More's Utupia and Cicero's De finibus bonorum et malorum», Moreana, 51/195-196, pp. 63-84.

Trousson, RAYMOND (1995). Historia de la literatura utópica. Viajes a países inexistentes, Barcelona, Península.

Voltes, Pedro (2013). Tomás Moro. Utopía, Barcelona, Austral (epub). 